\title{
Leisure centre entrance charges and physical activity participation in
}

\section{England}

Ward, F., Researcher, Division of Health Research, Faculty of Health and Medicine, Lancaster University, Lancaster LA1 4YW, UK

Halliday, E., Senior Research Fellow, Division of Health Research, Faculty of Health and Medicine, Lancaster University, Lancaster LA1 4YW, UK*

Barr, B., Senior Lecturer, Department of Public Health and Policy, University of Liverpool, Liverpool L69 3BX, UK

Higgerson, J., Research Fellow, Department of Public Health and Policy, University of Liverpool, Liverpool L69 3BX, UK

Holt, V., Senior Research Associate' Senior Research Fellow ${ }^{1}$, Division of Health Research, Faculty of Health and Medicine, Lancaster University, Lancaster LA1 4YW, UK

*Address correspondence to Emma Halliday: e.halliday@lancaster.ac.uk

\section{FUNDING}

This work was supported by the NIHR School for Public Health Research (SPHR) [grant number SPHR-LIL-PES-LAL]. The views expressed are those of the authors and not necessarily those of the NHS, the NIHR or the Department of Health.

\section{ACKNOWLEDGEMENTS}

We wish to acknowledge the support of participating local authorities to the research and residents of these neighbourhoods who took part in the study's fieldwork and public involvement activities.

\section{WORD COUNT INCLUDING BREAKDOWN}

Title: 10/10 words

Abstract: 250/250 words

Full manuscript (excluding title page/abstract): 6618 words

\section{ETHICS APPROVAL}

Ethics approval was gained from Lancaster University's research ethics committee in December 2014 (FHMREC14025). 


\begin{abstract}
Reducing or eliminating the cost to the public of using leisure facilities is one tool that local authorities have available to reduce inequalities in physical activity (PA). There is limited evidence about the effect of leisure entrance charges and their impact on participation. This study aimed to ascertain how facility pricing influenced the decisions people made about how to pay and what to pay for and how, in turn, these decisions impacted on participation for different groups. A total of 83 members of the public living in four local authorities in the North West of England were involved in focus groups or individual interviews. The results show that cost was a key factor which influenced PA participation in low income neighbourhoods. In practice, however, the majority of service users navigated the range of prices or payment options to find one that was suitable rather than simply reporting whether leisure was affordable or not. Whilst pre-paid options (e.g. direct debit memberships) encouraged participation, entrance charges incurred each time an individual participated had a negative impact on frequency but were a convenient way of paying for occasional use or for people who were unable to afford a pre-paid option. Free access also helped people who could not afford pre-paid membership to exercise regularly as well as incentivising non-users to try activities. The research concluded that policies that include components of free access and offer more flexible payment options are most likely to contribute to reducing inequalities in PA.
\end{abstract}




\section{INTRODUCTION}

The health consequences of physical inactivity are well established with sedentary behaviours associated with a range of chronic illnesses and early deaths (World Health Organisation, 2010). Inequalities persist in physical inactivity (PA) with disadvantaged groups more likely to be inactive than those who live in more affluent circumstances (Public Health England, 2014). Yet despite a growing body of research on PA interventions, much of this has focused on the effects of individual level behavioural interventions rather than community level actions to address determinants that influence or constrain behaviours (Ball et al, 2015).

Existing studies show a range of factors impact on levels of PA, including structural, interpersonal and intrapersonal influences (Raymore, 2002) and that these affect participation by different populations in different ways (Audrey et al, 2012; Devereux-Fitzgerald et al, 2016; Bhatnager et al, 2015; Pan et al, 2009). Cost is just one of the structural variables but one that may be a significant barrier, particularly in lower income neighbourhoods (Adams \& Steer 2016). Systematic reviews of qualitative studies exploring public perspectives on PA (e.g. Allender et al, 2006; Devereux-Fitzgerald et al, 2016) have drawn attention to the cost of participation alongside other factors (e.g. accessibility and acceptability). Cost is also a barrier to access for people on minimum incomes (Burgoyne et al, 2008), although a study of an inner city Exercise Referral Scheme found that whilst cost was a barrier for some participants, the low cost in this case did not encourage adherence (Tai et al, 1999).

Local authority (LA) or municipal leisure facilities are an important setting where PA can be supported. Interventions that offer free or subsidised access to leisure in this context may include free swimming initiatives or concessionary entrance charges for particular groups (e.g. adults in receipt of welfare payments). However, evidence from interventions studies is mixed, with research having found that reducing or removing the price of participation may encourage teenage children to swim (Audrey et al, 2012) but is less important for older adults (Kokolakakis et al, 2015). A reduction in cost may have a more positive impact in the short term (Coalter, 2006), for those already exercising (e.g. Bullough et al, 2015) or for particular activities (Anokye et al, 2014). Studies have also suggested that people who were previously 
inactive and were encouraged to participate in free sessions often returned to inactivity once the free provision came to an end (Adams \& Steer, 2016).

Within the current body of PA research, an in-depth understanding of the range of pricing options available to communities and the implications of these for actions to tackle PA inequalities is lacking. This research aimed to investigate public perceptions of entrance charges and how the charges influenced participation by adults living in lower income neighbourhoods in England. It forms part of a larger mixed method study which has included interviews with leisure and public health policy makers and analysis of leisure transaction data to investigate how pricing decisions are set and quantitatively assess the differential effects of price.

\section{METHODS}

\section{Location}

Four local authority areas (LAs) in North West England were included in the qualitative research, all in areas of significant socio-economic deprivation. Purposive sampling was also used to select areas where differences were identified between leisure entrance charging policies. For example, in Area 2, free leisure was available to anyone living and working in the LA. Free leisure formed part of the leisure offer for children in Area 1 and Area 4, however, few free offers were available for the public in Area 3.

\section{Participants}

Fieldwork was conducted by researchers (initials to add) between October 2015 and April 2016. Face to face recruitment in leisure centres took place at various times of the day and evening to reach different groups. In neighbourhood settings, recruitment was facilitated by community workers or members of the public with local community links who helped negotiate access and set up groups.

Participants were over 18 years old with the capacity to consent. Young people under 18 years were excluded as it was anticipated that in most cases, parents/guardians would be responsible for paying entrance charges. Purposeful sampling aimed to capture perspectives from across the life course (older adults, working age, families) 
as well as non-users of facilities. Diversity was also sought in the sample with respect to gender and ethnicity.

In total, 83 participants were recruited - 63 people took part in focus groups and 20 in telephone interviews. The overall sample included a mix of economically active and inactive people of working age, students and retired adults. The majority of the participants were regular users of the leisure centres, attending at least once a week, but there were also 15 participants who attended community based leisure activities run by the LA and 13 people who did not use the leisure centres or used them only infrequently. Participants paid for leisure centre activities in a range of ways, including pre-paid membership (usually peak or off-peak, sometimes with concessionary rates), paying each time the service was accessed (pay-as-you-go or PAYG) and using free leisure sessions where these were available.

Table 1 to be inserted here

\section{Data collection}

Participants were given an information sheet and asked to sign a consent form prior to the interview or focus group. In one group, a community facilitator acted as a translator where the group were comprised mainly of non-English speakers. A semistructured schedule was used to guide discussions. Participants were asked about their pattern of PA participation, their motivation to use facilities and the factors that influenced attendance including views on facility entrance charges and concessionary schemes. The interviews also sought to contextualise price as part of people's everyday lives given cost/affordability was likely to be only one of the many factors that influenced decisions to participate.

\section{Data analysis}

Interviews were recorded and professionally transcribed. To manage the volume of data generated within the research's timescales, the researchers followed principles of framework analysis, which involved summarizing data to a set of analytical frameworks, used as basis for cross case analysis (Gale et al, 2013). During this process, researchers initially familiarized themselves with the data by reading 
transcripts before producing short memos for each interview or focus group. This immersion process was used to note down key ideas and recurrent themes with excerpts from the data included to illustrate concepts. These memos, produced for each transcript, were then used as the basis for agreeing upon a framework for data extraction. The data extraction framework was systematically applied to all transcripts and tested by two researchers (initials here) on a subset of transcripts. The completed data extraction frameworks were then uploaded to NVIVO 10 and coded so they could be used as the basis for assembling and organising data into a set of analytical charts.

The analytical charts were studied to map connections between themes (e.g. relationship between affordability and payment methods). Analysis of focus group data particularly sought to identify divergence or minority perspectives between group participants. Discussions were then conducted within the team to identify potential explanations and interpretations. In the last stage, respondent validation was undertaken (Silverman, 2006) where five members of the public (study participants) took part in a workshop in August 2016 to discuss and offer feedback on preliminary research findings.

\section{FINDINGS}

The thematic analysis identified three dimensions - affordability, value and motivation - to help explain the interplay between the role of leisure pricing and the decisions people made about how to pay and what to pay for and how, in turn, these decisions influenced participation for different groups.

\section{Affordability, price and payment method}

Participants could be grouped according to whether entrance charges were not an issue affecting use, those who felt the cost of using leisure centres was prohibitive and people who were able to afford to use facilities but were constrained by price when making decisions about how to pay or whether to take part in an activity. 
Price not a significant factor

For a small number of people, the amount they paid to access leisure facilities was not an overriding consideration. These typically were users who were employed and accessed the centres at peak-times with a pre-paid membership. They were inclined to be positive about what they were getting for their money - they were happy with the opening hours, the range of activities offered and they appreciated the flexibility of being able to attend other centres if they wanted to do a class, for example, at a different time. One of these people spoke about the price of membership in the following way:

"In all honestly we're pretty happy because we've actually lived away for a little while; we lived in New Zealand for a year and the gym membership we paid there was quite expensive. So coming back here and paying £26 each a month we kind of think it's not too bad you know.”(M, employed: FW_int_4b)

Price as a barrier

At the other end of the spectrum were a number of participants who indicated that price had a direct bearing on the likelihood of them using a leisure centre at all. This view was most prominent among those using universal free leisure sessions available for anyone living or working in one area (Area 2), a group of people given time limited free access passes as a thank you gift for their volunteering in a second area (Area 3) and those occasionally attending through PAYG (all areas). Low household incomes were identified as a particular barrier, affecting people on pensions, those receiving unemployment welfare payments and working families as two participants explained:

"a lot of people is out of work and that; ... if they are having to pay and it's coming out of their benefits it's not going to work; they stop bothering because it's costing too much.” (M, unemployed: FW_int_2a)

"I am not saying it's poor; there are some areas that are poor and there are some areas that are wealthy but a lot of people wouldn't use the facility if they had to pay all the time. If you look at the demographics of the people using it you will see that maybe $60 \%$ are of retirement age and probably couldn't 
afford to go if they paid all the time and therefore wouldn't use the facility or wouldn't get that health benefit from it." (M, working: FW_int_2b)

The volunteers with time limited free passes suggested that entrance charges were prohibitive even with the available concessions and that they would not have been able to attend without the availability of free (or much cheaper) access. A comparison was made by one of these participants between the cost of using the leisure centre and essential expenses:

“They can’t really afford it on the job seekers; you only get $£ 73.10$ to run a whole house, pay all your bills, buy all your food. Even $£ 1.50$ is like milk and bread and you just want to keep active and the amenities are there but can't afford to go in." (F, not working: FW_fg_3b)

Participants from another focus group conducted in the same area agreed that the concessionary rates were inadequate given low income levels in the local community. This was perceived to be reflected in underuse of the facilities as one unemployed participant explained:

"I don't think the discount is that big to be honest where people are unemployed. If anything I think they could do more to help people because when you're on job seekers allowance and you're living on your own it is expensive to go over there. A lot of times you go over as well it can be quite empty so I feel if they reduced the prices surely a lot more people would go wouldn't they." (F, unemployed: FW_fg_3d)

More generally participants from all areas gave examples of acquaintances unable to afford the entrance charges that they themselves paid. When one person had tried to encourage a neighbour to attend, the response, on being told the price, was 'she says well that would mean a choice between exercising and eating' (F, retired: VH_fg_1a). Other people referred to 'friends who wouldn't come because of the money' (M, retired: VH_fg_1a) and 'a family that would love to come but they just cannot afford to' (F: EH_fg_3b). Current users were also mindful of the impact that prices increases could have. In one area where changes to the concessionary pricing had resulted in an 
increase to entrance charges, participants felt that inactive people might be discouraged from attending:

"I am aware that a lot of people do see the cost as a barrier. Once they start to use the facilities they probably say it's good value but it's a big barrier to entry if you like to get people in." (M, retired: EH_fg_3b)

A minority of participants suggested entrance charges were fairer for some groups than other. For example one participant argued that there was a lack of parity in the amount that older people were charged compared to those who were working:

"For when you're 60 or in retirement ... it should be cheaper. Why should we pay the same as all of them what are working on good salaries and all that? I think that's one big problem.” (F, retired: VH_fg_1a)

However, participants in several focus groups in all areas shared a view about the role of cheaper pricing to encourage more children to exercise. Free swimming was seen to be particularly important in getting parents to exercise with their children. Free swimming was available for all children in one area and during school holidays in others. However, its withdrawal in another locality was seen as a significant loss as people felt that a lot of families would not be able to afford to pay for swimming, particularly if they had more than one child.

Price as a constraint on choice Another perspective expressed was that the entrance charges were reasonable, though not insignificant. Participants revealed how they had researched the pricing options or looked at ways of trying to make it more affordable (including seeking a referral from their doctor to get a discounted rate) and spoke about the importance of making a considered decision:

"If it was a smaller amount of money you wouldn't be bothered would you ... but because it's a considerable amount; it's £20 odd.” (M, retired: VH_fg_1a) Timing of participants' use of leisure centres was often governed by the cost. Using facilities at off-peak-times was the main way that attending became more affordable 
for a number of participants: whilst for some, particularly retired participants, it was a positive choice to attend during the day, others only went at off-peak-times because they could not afford peak-time prices. One recently retired person explained how this had affected her participation choices:

"The cost is a problem for me now I'm retired and I have less income so I've taken out the $£ 15$ a month but that restricts me; I've got to be between 9 and 4 o'clock so there are sessions in the evening that I would have to pay and that would be $£ 5.50$ a time.” (F, retired: FW_fg_4a)

For some participants, commitments such as studying, work or childcare had meant they could not attend at off-peak-times and with peak rates being seen as unaffordable, the result was that they did not attend at all. Several participants spoke about the differential charges in terms of fairness suggesting that peak-time rates 'penalise people who work and don't have a choice about when to come' (F, employed: FW_fg_3b); another person said that 'because you work doesn't mean you have got a spare $£ 40$ or $£ 50$ to go to the gym’ (F, student: FW_int_3d). For others, concessionary rates such as a student membership made peak-time access affordable although one person was unsure if he would be able to pay the peak-time rate even when he got a job.

Although PAYG was seen by most participants as an expensive option if used regularly, it was suggested that it could make peak-time attendance affordable for some. One person spoke about her daughter who had a learning disability - she had to use PAYG because she could not exercise during the day and the pre-paid peak-time membership was too expensive:

"She doesn't go in the day time because she go to day centre but ask me pay $£ 300$ [for annual peak-time membership] you can go anytime. I won't pay for that." (F, working age: FW_fg_4a)

In one area where free leisure access was not provided by the LA, a minority chose PAYG because it was 'less financially demanding' than an annual membership. They felt that a monthly membership was too much to pay at once so PAYG was seen as 
the only option if the wanted to use the leisure centre, although the view was that the cost 'starts to add up' if wanting to attend regularly.

In addition to influencing when people went, the pricing structure frequently influenced what they took part in at the leisure centres. Some participants cited the cost of classes as an unaffordable extra to their pre-paid membership:

“You're paying like $£ 4$ or $£ 5$ a class and you want to do it two or three times a week its $£ 15$ and then it's not included in your membership and then you're paying a membership on top of that. So it can get quite expensive." (F, employed: FW_int_3e)

Another participant explained she had to 'draw a line' and so did not go to Zumba classes, saying 'I can't afford everything'. She had also changed her membership as she needed to use a gym for health reasons and now attended a different centre to her husband and son because it offered a cheaper rate at peak-times. This now prevented the family from swimming together, an activity they had previously enjoyed:

"So it's kind of taken that family time that we had together away. Then at the same time I think in a busy life style we just try and fit in what we can as we can to try to be active I guess.” (F, employed: FW_int_3c)

\section{Value and motivation}

The cost of accessing facilities and the payment method used had an impact on the way that people valued leisure centres and on their motivation to be active. The price, the payment method and cost relative to what was provided, in relation to the personal benefits and in comparison with other facilities were all important.

Using pre-paid membership

Whilst participants saw a monthly membership payment as a significant financial commitment, using leisure facilities regularly, increased the personal value people attached to it. The monthly cost was typically considered as good value if used:

"You make your money back very quickly to be honest if you look up paying individually. I suppose that's the same for the gym, I mean, I took it on the 
nose that it doubled in price to what I was used to paying but if you look at how if I didn't have the monthly pass I get my benefit out of it. I don't fall short should I say...Come the end of the month I feel like I've exhausted that $£ 23$ and so I feel like the council gives me something back in a way.” (F, employed: FW_int_3c)

Pre-payment also appeared to encourage on-going participation. Participants frequently referred to the cost per session reducing each time they attended, one citing this as 'another incentive'. Two retired participants explained how their pre-payment motivated them to attend the centre regularly:

"Because I pay by direct debit you know I try and come twice a week when the classes are. Otherwise I am just throwing money away." (M, retired:

VH_fg_1a)

"You might as well make use of it. I think there is an encouragement in that and you think $£ 18.50$ and I haven't been it does encourage you to go.” (M, retired: EH_int_2h)

Pre-payment for exercise classes was an additional motivation for one participant to attend. She liked the idea of reserving a place as she felt it was an added incentive, saying 'I have made an agreement with myself really as well as the gym'. (F: not stated, VH_fg_1b)

In some areas, pre-paid passes were available for particular activities, such as swimming or the gym. These were seen as particularly good value by people who only wanted to do one activity but do so regularly. One mum who planned to use the gym whilst her son was at a swimming club saw the cost as being very reasonable given time she planned to exercise:

“I think £24 that's only $£ 6$ a week, which isn’t a lot really if I’m at the gym for 10 hours a week." (F, student: FW_int_4e) 
Another participant at the same centre who swam at least five times a week viewed the cost of his annual swim-pass positively in comparison to the amount paid on the door (PAYG):

“I think it’s about $£ 4$ per swim, so I would make my money back in a few months really." (M, employed: FW_int_4f)

Value was also attached to the flexibility that pre-paid membership of a LA leisure centre could bring in terms of opening times, the range of activities and access to different venues:

"I know that I can go at any time; I can go in the gym, in the bath, if I want to go to any other things ... I can go to them all. But for me it's very reasonable. If someone is only using it once, of course, once a week then perhaps it wouldn't be but I find it very reasonable." (F, retired: FW_int_2e)

A user who had peak rate membership and could be flexible about where they attended was similarly positive:

"So it's quite nice that way because there are so many different locations ... we use the classes, we use the gym and we use the swimming pool so we pretty much get our monies worth to be honest." (M, employed: FW_int_4b)

The financial commitment of pre-payment, however, was not a sufficient motivation for some people and other commitments such as a new job, a change in working hours, studying or childcare sometimes meant that it could no longer be justified. One mature student who paid monthly for a gym pass explained her experience in the following way:

"I have sort of learnt myself over the past few years what I'm like so I don't think I would get out another contract gym membership ... I know that when I get too busy the gym will get forgotten about and I'm just wasting my money then. So I don't think I would pay it." (F, student: FW_int_4e) 
The value attached to pre-paid membership was also seen to decline if other factors such as ill health or family commitments prevented participants from exercising or, in one group, if participants felt they were 'subsidising' activities they did not use.

"I also think it should be separated out more because that's one of the things you want to go in the [Scheme] and you have to pay for everything else and I think that's wrong...you are paying for things that you don't actually use." (F, employed: VH_fg_1a)

However, this view was not a dominant theme among all participants interviewed in this area; with others suggesting that what they paid for their membership was felt to be good value.

Pay-as-you-go

As highlighted above, PAYG was viewed by participants to be expensive and a payment method that was not good value. In this respect, it discouraged frequent attendance even when someone was motivated to exercise regularly:

'... if you are trying to keep healthy and that is costing you a fortune really.'

(M, unemployed: FW_int_2a)

In some cases, participants reported moving from PAYG to a membership. A participant who swam 4 or 5 times a week explained how he had moved to an annual swim pass to save money as soon as he was '... more sort of motivated and it was becoming part of my routine" (M, employed: FW_int_4f).

Free leisure

Public views were mixed about the perceived value of free LA leisure provision. In one LA area, free leisure sessions were available universally for the entire local population and had been introduced to tackle high levels of inactivity. These sessions were highly valued by leisure users in this area and were seen to reduce or remove the affordability barrier for people on a low income due to unemployment, low wages, or retirement. 
Removing the price barrier through the provision of free sessions was also reported to play a role in encouraging attendance for inactive people. One community group leader suggested it was an important motivation for people she knew:

"I mean some of the ladies from other sessions say that if they'd never been free they would never have started exercising. It encouraged them to take part in something." (F, employed: EH_fg_2a)

A participant who was attending time-limited free sessions via a GP referral scheme echoed this view, suggesting that the fact that it was free had encouraged him to start exercising and he was now thinking about attending the leisure centre more often:

"If I could use the gym at my own discretion I would be there every night but obviously I have got to pay for that so I'm trying to utilise the fact that its free is a motivational thing on its own for me personally." (M, employed:

FW_int_2c)

There was also some evidence that the ongoing availability of the universal free sessions had encouraged people to use the leisure centres more frequently. For one participant, for example, using free provision had encouraged him to attend more often and he recognised that the cost would be significant if he had to pay:

"Because the swimming is free it's an incentive for me to swim more often and sometimes I've done that 3-4 times a week. Not always, I generally do a couple of times a week but sometimes I have done sort of every other day and then the sort of $£ 4$ starts to add up a little bit don't it." (M, retired: FW_int_2d)

But the fact that the sessions were free was not always the overriding motivation that governed whether participants would exercise. Some people who took advantage of the universal free sessions suggested they would pay for a session if work/other commitments had prevented them attending during a free slot or they wanted to use the leisure facilities:

"It depends on my mood really; if it's not free I'll just go and pay." (M, unemployed: FW_int_2a) 
A retired participant who usually attended the free sessions saw them as 'a bonus' (F, retired: FW_int_2e) as against the PAYG rate which she had previously paid but was also cognisant of the scheme's relevance in a community with high unemployment:

"I think it's massive because people who only work part time or don't have a job at all they can go and if they don't have to pay then there's no disincentive is there really. They are the sort of people who probably would access it if they didn't have to pay." (F, retired: FW_int_2f)

In areas where free leisure was not available, some participants suggested that the provision of free leisure sessions may have negative consequences. In contrast to the widely expressed view that pre-payment encouraged commitment, participants in one group suggested that free provision might not be valued and would not result in regular attendance:

"If it was free, you might treat it, not with contempt but I don't have to bother because it doesn't cost me anything." (M, retired: VH_fg_1a)

And whilst the free sessions were valued by those using them, several people said they appreciated the fact that this provision had financial implications for the service provider. One user who was working but attended free sessions could see both sides of the picture:

"If they had more times that were free I think it would be very difficult because they have to make money. I completely understand that but they have lots of free sessions and I think it's good that they do.”(M, employed: FW_int_2b)

Personal benefits

Whatever the method of payment, the value of attending a leisure centre increased as a consequence of a positive experience, including improvements in physical and mental health and the social networks formed with other users. These social contacts also motivated users, particularly retired people. One person who used the gym spoke about the camaraderie of fellow participants

'I think it's not only it's healthy; it's amazing because it becomes a social thing as well ... because you to the gym at the same time every morning and 
you see the same people there or similar people there if you go late; it becomes a social event really.' (M, retired: EH_int_2h)

And another participant related the increasing value of contact with other people at the leisure centre in her retirement:

"Since I've retired I realise just how much I never thought I would miss work; that was my social life but I think just coming here just to mix with other people” (F, retired: $\left.\mathrm{FW} \_f g \_3 \mathrm{c}\right)$

\section{Facilities}

Value was also attached to leisure centre staff who understood the needs of the range of users and created a welcoming atmosphere:

"We feel very comfortable there; when the people feel comfortable of course we would like to return again and again.”(M, student: FW_int_4c)

For others including women from ethic minority backgrounds and people with a physical disability, knowledge about the activities offered and the physical environment (including accessibility in the pool areas, privacy in the changing rooms, and women only sessions) were reported to have as great a bearing on participation decisions as the cost of attending.

\section{DISCUSSION}

This study found that the affordability of leisure was a barrier that prevented some groups from taking part at all and for others acted as a constraint to regular participation. A minority suggested that the entrance charges they paid was not an issue and were able to pay peak rates and use all of the available facilities in a flexible way. Experiences of charges were most often frequently expressed in terms of navigating the range of prices or payment options available rather than simply whether leisure was affordable or not. Many participants felt constrained by what they were able to afford and selected a membership package that they felt able to pay for and made the most of the option they had to take. Once they had committed themselves to pre-paid membership, participants typically reported that this was good 
value for money and their level of PA increased. They were encouraged to attend regularly because they had paid in advance and because they experienced a range of social, psychological and physical benefits. The value of pre-paid options was seen to decline if use of facilities reduced, often as a result of family or job commitments among working age adults.

PAYG, while not requiring users to commit to a regular direct debit payment, was only viewed positively by people who paid occasionally to supplement their attendance when a free session was not available or by new users who were initially unsure about how often they would attend. PAYG was also the only option available to people on low incomes whose personal circumstances meant they needed to use the centres in the evening but could not afford the peak-time membership rates. The findings support previous work which suggests that PAYG entrance charges, incurred each time an individual participates, is a key element which has an impact on the frequency of participation (Gratton \& Taylor, 1994).

Where the cost of paying entrance charges was prohibitive, leisure users described making use of free sessions where available and many indicated they would not be able to attend if sessions were not provided. Free sessions were also highlighted as a way of incentivising non-users to try out activities and enabling people wanting to exercise regularly but were unable to afford pre-paid options - less frequently they were seen as a 'bonus' for existing users. Free swimming provision also made attendance affordable, especially when a family had more than one child. But if free sessions were time limited for a set period of time rather than offered on an ongoing basis, the research supported previous findings that this would often result in a return to inactivity (Adams \& Steer, 2016).

This research also supports existing evidence that leisure centre users often had to overcome other barriers alongside cost, before they accessed the facilities (Raymore, 2002). Previous research has indicated that travel to leisure centres can be a significant additional cost (Anokye et al, 2014) but in this study people were more likely to speak about travel in in terms of accessibility rather than cost. It was evident that people on lower incomes who needed to walk or travel by bus were more 
constrained and had to use the nearest facility unless they could rely on a friend for a lift: they did not have the flexibility of using other centres for different activities or for sessions at more convenient times and so were less likely to participate if the nearest provision was not suitable. The findings confirmed other recent research that identified accessibility (location, environment and provision) played a particular role in influencing the use of facilities amongst socioeconomically disadvantaged groups, people with physical disabilities and women from ethic minority groups (Smith et al, 2015).

Although caution is needed as the study recruited only a small numbers of non-users, the findings reflect previous research, which suggests that people who did not use the leisure centres were likely to see the membership and entrance prices less positively (Coalter, 2004): non-users appeared not to appreciate the range of benefits which came from participation and may have stereotypical views about what municipal leisure centres offered.

\section{Limitations}

There were limitations in the recruitment of participants to the study. Leaving project flyers in leisure centres and mail outs by the leisure service on behalf of the research team elicited a limited response. Face to face recruitment was difficult when people were in a hurry to attend a class or were there with children, particularly when recruitment took place in the evenings. Older (often retired) adults and females were over represented in the sample and non-users under-represented. It is recognised that non-users may have expressed different perspectives on the role of price (Coalter, 2004). Where recruitment from ethnic minority populations was supported by community workers in one area, this resulted in the recruitment of mostly non-English speaking female participants involved in a community based activities who were not necessarily representative of the general population. The nature of recruitment and time constraints of participants meant there were difficulties in collating more detailed participant demographics beyond age and gender. Although this is an acknowledged limitation, employment status was frequently self-disclosed by participants during discussions about whether or not this affected their use of centres. Discussions with 
women from different ethnic backgrounds also indicated that issues of accessibility and acceptability were more important than cost in affecting participation.

\section{CONCLUSION}

This research supports the view that cost is one of the factors which influences levels of PA in low income neighbourhoods but also highlights the importance of the range of entrance charges that are available when considering the impact of price on the use of LA leisure centres. The research also found that price can be important in encouraging sustained levels of PA, including for people who were previously physically inactive. Further qualitative work located in socioeconomically neighbourhoods should investigate attitudes to leisure facilities and PA more generally among all groups who do not meet recommended activity levels. It would also be beneficial to undertake further research with those who exercise at home or at community/private facilities and classes to understand why they chose these options rather than LA facilities.

Public organisations that commission or deliver PA interventions and services should consider options that enable people to more easily afford to participate in wider range of activities. This could include cheaper PAYG options for those who cannot commit to pre-paid membership, free sessions on offer at a range of times and affordable provision in peak-times for those on low incomes or who work 'non-regular' hours. However leisure services and interventions may also risk increasing inequalities if barriers to accessibility and acceptability for different groups are also not adequately addressed alongside cost.

\section{CONFLICTS OF INTEREST}

None 


\section{REFERENCES}

Adams, EJ. \& Steer, R. (2016). Leicester-shire get healthy get into sport final evaluation report. BHF National Centre for Physical Activity and Health, Loughborough University, Loughborough, UK.

Allender, S., Cowburn, G., \& Foster, C. (2006). Understanding participation in sport and physical activity among children and adults: a review of qualitative studies. Health education research, 21(6), 826-835.

Anokye, N. K., Pokhrel, S., \& Fox-Rushby, J. (2014). Economic analysis of participation in physical activity in England: implications for health policy. International Journal of Behavioral Nutrition and Physical Activity, 11(1), 1.

Audrey, S., Wheeler, B. W., Mills, J., \& Ben-Shlomo, Y. (2012). Health promotion and the social gradient: The free swimming initiative for children and young people in Bristol. Public health, 126(11), 976-981.

Ball K, Carver A, Downing K, Jackson M, O'Rourke K. (2015), Addressing the social determinants of inequities in physical activity and sedentary behaviours. Health Promotion International; 30:ii8-ii19.

Bhatnagar, P., Shaw, A., \& Foster, C. (2015) Generational differences in the physical activity of UK South Asians: a systematic review. International Journal of Behavioral Nutrition and Physical Activity, 12(1), 1.

Bullough, S., Davies, L. E., \& Barrett, D. (2015) The impact of a community free swimming programme for young people (under 19) in England. Sport Management Review, 18(1), 32-44. Burgoyne, L. N., Woods, C., Coleman, R., \& Perry, I. J. (2008) Neighbourhood perceptions of physical activity: a qualitative study. BMC Public Health, 8(1), 1.

Fred Coalter (2004). Reference pricing: changing perceptions of entrance charges for sport and recreation. Managing Leisure, 9(2), 73-86

Coalter, F (2006). Free swimming: A need for a more strategic approach. University of Stirling, UK.

Devereux-Fitzgerald, A., Powell, R., Dewhurst, A., \& French, D. P. (2016) The acceptability of physical activity interventions to older adults: a systematic review and meta-synthesis. Social Science \& Medicine, 158, 14-23. 
Gale NK, Heath G, Cameron E, Rashid S, Redwood S. (2013) Using the framework method for the analysis of qualitative data in multi-disciplinary health research. BMC Medical Research Methodology, 13(1), 117.

Gratton, C., \& Taylor, P. (1995). From economic theory to leisure practice via empirics: the case of demand and price. Leisure Studies, 14(4), 245-261.

Kokolakakis, T., Pappous, A. S., \& Meadows, S. (2015). The Impact of the Free Swimming Programme in a Local Community in the South East of England: Giving with One Hand, Taking Away with the Other. International journal of environmental research and public health, 12(4), 4461-4480.

Pan, S. Y., Cameron, C., DesMeules, M., Morrison, H., Craig, C. L., \& Jiang, X. (2009). Individual, social, environmental, and physical environmental correlates with physical activity among Canadians: a cross-sectional study. BMC public health, 9(1), 1.

Public Health England (2014), Everybody Active, Every Day. An evidence-based approach to physical activity. London: Public Health England.

Raymore, L. A. (2002), Facilitators to leisure. Journal of Leisure Research, 34(1), 37.

Silverman, D. (2006). Interpreting qualitative data: Methods for analyzing talk, text and interaction, London: Sage.

Smith, B.J., Thomas, M. and Batras, D., (2015). Overcoming disparities in organized physical activity: findings from Australian community strategies. Health Promotion International, p.dav042.

Tai, S. S., Gould, M., Smith, P., \& Iliffe, S. (1999), Promoting physical activity in general practice: should prescribed exercise be free?. Journal of the Royal Society of Medicine, 92(2), 65-67.

World Health Organisation, (2010) Global recommendations on physical activity for health. Geneva: World Health Organisation 